\title{
How to improve monitoring and forecasting of disease patterns
}

\author{
"The answer, my friend, is blowin' in the wind"
}

Throughout history, prophets and fortune tellers have predicted the weather and disease. Recent scientific advances have made us less reliant on prophets for weather prediction, but our ability to forecast the weather has far outstripped our ability to predict occurrences of disease. Why is this so? Shouldn't we in health care strive to accomplish what those in weather forecasting have achieved: accurate monitoring and forecasting locally, nationally, and internationally?

To cite an illustration, last year's hurricane Andrew was the most destructive hurricane ever recorded in the United States. It cut a swath across some of the most densely populated areas of the country, destroying tens of thousands of houses and leaving 250000 people homeless. ${ }^{12}$ Despite the scale of destruction only 14 people were killed. Prophets might say that this was a miracle, but records show that during this century the number of deaths from hurricanes has fallen sharply. ${ }^{1}$ The reasons lie in improvements in the weather forecasters' ability to monitor and predict the exact path, timing, and force of the hurricane. For Andrew, forecasters were able to predict 10-14 days in advance where it would strike. In contrast, the Texas hurricane of 1900 struck with virtually no warning, resulting in 6000 deaths.

During this century monitoring and forecasting the weather has become a science, permitting effective preventive measures. The meteorological model can provide us with many pointers to how we can improve the monitoring and forecasting of disease.

Classification systems and instruments-Instruments such as the thermometer and barometer enabled standardised, accurate, and cost effective measurements of weather conditions even in the most remote locations. ${ }^{34}$ For diseases there are standardised and reasonably accurate classification schemes, such as the International Classification of Diseases, yet the current systems for monitoring health are either too inaccurate (for example, the communicable disease reporting systems), too costly (non-communicable disease screening or registries), or too slow (death certificates)..$^{5-7}$

Telecommunication systems-Part of the rationale for developing the global telegraph system in the mid-1800s was the transfer of information about the weather. ${ }^{4}$ Using information supplied by these telegraphs, national weather bureaus provided timely forecasts to local areas. Interestingly, 150 years later we are just beginning to discuss and implement telecommunication systems for monitoring diseases. ${ }^{8}$

Networking-Some of the first weather monitors were military doctors who reported weather conditions to the army's central weather centres. ${ }^{4}$ A network of cooperative field stations developed for collecting standardised data on weather. National and international societies sprang up. Currently, people who count and forecast diseases are scattered across many different agencies with little communication and no linking network.

Government recognition-Another reason for the success of meteorology was government recognition of the need for central weather bureaus to "provide useful warnings and information about various meteorological phenomena." 4 Few governments have central bureaus dedicated exclusively to timely collection of standardised local and national data on all major diseases and rapid forecasting. National disease monitoring bureaus need to be established to perform similar functions to those of national weather bureaus.

Systems perspective-Forecasters view weather from a "systems" perspective, whereby patterns are examined, mapped, and used for forecasting. Thus an individual thunderstorm is important in the overall context of weather patterns and systems. In health care we have focused on individual diseases rather than taking a systems perspective. Nevertheless, the interrelations between diseases in a population follow systematic and predictable patterns.

Standardised approaches to mapping - In weather mapping, simple nomenclature and symbols evolved that the military, government, and local newspapers could all use. While weather maps in newspapers or on television help us to understand and predict the weather, such a standardised approach to portray disease has not yet evolved, probably because the data on morbidity have been so poor. Once better data are fed into the system, however, approaches to mapping will need to be established. Every day weather forecasters give us the odds of a storm. Shouldn't our disease forecasters every day give us the odds of an attack of hayfever, the odds of our children developing a cold and not going to school, or the odds of injury when driving to work on wet roads?

International cooperation-In 1873 the International Meteorological Organisation met in Vienna and agreed on standards. In health we have accomplished this for death certification and disease classification but for little else. An international society for disease monitoring and forecasting thus needs to be formed to set standards of monitoring morbidity.

User demand-Perhaps the most important reason for the rapid development of weather monitoring was that many different groups demanded weather forecasting for economic 
reasons. Farmers demanded weather forecasts because adverse weather could lead to economic doom if crops were not harvested before a hail storm. International maritime cooperation was stimulated with one of the first economic analyses, which showed that marine meteorological charts produced annual savings in the 1800 s of between $\$ 40 \mathrm{~m}$ and $\$ 60$ m worldwide. ${ }^{5}$

Airlines recognised the importance of accurate weather forecasts for safety and profit. In contrast, governments, industry, and the public have not clamoured for better forecasting of disease as the economic importance of improved prediction may not be obvious. But, given the current costs of care, information concerning current and future disease patterns are critical for planning individual and industrial strategy. Moreover, the accurate monitoring of disease is important for governments as they have to decide how to allocate their scant resources for health care.

We are fast approaching the twenty first century with techniques towards monitoring and forecasting disease patterns that have changed little since the $1800 \mathrm{~s}$. These need revamping: the model of weather forecasting may be the way forward.

RONALD E LAPORTE Professor

Department of Epidemiology,

University of Pittsburgh,

Pittsburgh, PA 15025,

USA

1 Facts on File 1992;27:629.

2 World Almanac. New York: Shripps Howard Company, 1993.

3 Whitnah DR. A history of the United States weather bureau. Urbana: University of Illinois Press, 1961.

Hughes P. A century of weather service: a history of the birth and growth of the national weather service, 1870-1970. New York: Gordon and Breach, Science Publishers, 1970.

5 LaPorte RE, McCarty DJ, Bruno G, Tajima N, Baba S. Counting diabetes in the next millennium application of capture-recapture. Diabetes Care 1993;16:528-34.

6 LaPorte RE, McCarty DJ, Tull ES, Tajima N. Counting birds, bees and NCDs. Lancet 1992;339:494-5.

7 Directors of the WHO Non-Communicable Disease Collaborating Centres and Key Officials. Needed: universal monitoring of all serious diseases of global importance. Am f Public Health 1993;83:941-3

8 Birkhead G, Chorba TL, Root S, Klaucke DN, Gibbs NJ. Timeliness of national reporting of communicable diseases: the experience of the national electronic telecommunications system for surveillance. Am f Public Health 1991;10:1313-5.

\section{AIDS: global lessons from a global epidemic}

\section{New international threats demand international responses}

The central lesson of the global epidemic of HIV infection is that the world is still extremely vulnerable to the emergence and spread of infectious agents. Yet despite this, action to prepare the world for the next pandemic has been hesitant, grounded in traditional surveillance methods and limited by preglobal thinking about the ecology of microbial threats to health. The response of science, public health, and society to the emergence and dissemination of new diseases has been too narrow.

Global HIV has spread from an estimated 100000 people infected worldwide in 1980 to nearly 20 million by early $1993 .{ }^{1}$ This has shown us how newly emerging pathogens spread globally-by enormous movements of people, the universality of sexual exchange, an international traffic in blood products, and the international epidemic of drug misuse. The dramatic increase in movements of people, goods, and ideas during the past quarter of a century has increased the opportunities for infectious agents to transcend borders. Paradoxically, two divergent directions of movementurbanisation and entry into previously uninhabited landshave both facilitated the emergence of new disease. ${ }^{2}$

A cluster of fortunate circumstances led to the relatively rapid recognition of the HIV/AIDS pandemic within a decade after the start of its widespread dissemination. Had the latency from infection to disease been longer, had human retrovirology not been sufficiently developed, had the pathogenic action of HIV led only to increases in common illnesses and cancers rather than to a very unusual syndrome, had the syndrome's occurrence been more initially diffused in the population, or had it not occurred in an industrialised country with an unparalleled capacity for national surveillance and communication, then the discovery of HIV/AIDS could easily have been delayed for an additional five to ten years, with enormous consequences for public health.

What of the future? We can be sure that expanding human influences on the natural environment at local, national, and even global levels will favour increased contact between humans and pathogens which are presently unknown or of limited geographical range or affect only other species. Once such pathogens enter a human population the increasingly transnational organisation of our economic, social, cultural, and political world gives them a chance for rapid spread.

More than 10 years of AIDS should have led to a new era of thinking about global vulnerability to new pandemics, but despite the excellent recent report by the United States Institute of Medicine, an aggressive and appropriate response has been slow to develop. ${ }^{3}$ By contrast to the dynamic nature of the problem, current proposals seem static. These have included establishing sentinel "centres of excellence" around the world and similarly entrusting the World Health Organisation with the responsibility for developing and coordinating an early warning system for the emergence of new diseases.

Unfortunately, the world remains unprotected by any semblance of a global system for anticipating, seeking, and identifying new microbial threats to health, let alone responding coherently to them. The central features of such a system would include

- global scientific leadership to recognise and publicise the danger of perpetuating the current ad hoc and highly fragmented disease surveillance system

- recognition that only a truly international system can be effective

- recognition that many factors affect the emergence of disease, including climate and environmental change; socioeconomic, political, and cultural processes; migration; commerce and shipping; and tourism

- a means of predicting where new microbial threats may emerge, based on an ecological understanding of conditions which foster such developments-with the focus more on the milieu than on the microbe

- a rethinking of surveillance strategies to include an analysis of how recent new pathogens have been identified and consideration of which types of data would most usefully identify changes in health patterns. Many disciplines and techniques (such as molecular biology, mathematical modelling, and remote sensing) must be combined with the perspectives of workers in primary care and local health. Collaboration is needed with social scientists, economists, and 